\title{
Abdominal aortic calcification score can predict future coronary artery disease in hemodialysis patients: a 5-year prospective cohort study
}

Hung-Chih Chen ${ }^{1}$, Wei-Ting Wang ${ }^{2}$, Chieh-Ning Hsi ${ }^{2}$, Che-Yi Chou' ${ }^{1}$, Hsuan-Jen Lin' ${ }^{1}$ Chiu-Ching Huang ${ }^{2,3}$ and Chiz-Tzung Chang ${ }^{2,3^{*}}$

\begin{abstract}
Background: Abdominal aortic calcification (AAC) has been known to be associated with cardiovascular mortality in hemodialysis. However, the association between AAC and future coronary artery disease (CAD) occurrence is not clear. We aimed to clarify the association of AAC severity and the occurrence of future CAD events in hemodialysis patients.

Methods: Hemodialysis (HD) patients were recruited in this prospective cohort study. AAC severity was quantified by AAC score, which was measured by lateral lumbar radiography. We used receiver operation curve (ROC) analysis to find the cutoff AAC value for CAD prediction. CAD-free survival was analyzed by Kaplan-Meier study.

Results: There were 303 patients recruited for study with a median (interquartile range) follow-up of 95 (65-146) months. The AAC score in patients with occurrence of new CAD [9 (3-15.25), $n=114]$ was higher than in patients without new CAD occurrence [5 (1-9) $n=189], p<0.001$. Multivariate hazard ratio of AAC score for CAD was 1.039 $(p=0.016)$. ROC study showed that an AAC score of 5.5 had a sensitivity of 0.658 and a specificity of 0.587 in the prediction of new CAD occurrence. Patients with AAC score above 5.5 had significantly higher cumulative incidence of $C A D$ than patients with $A A C$ score below 5.5. Age, diabetes, prior history of CAD, and longer dialysis vintage were major factors associated with higher AAC score.

Conclusions: AAC score can predict the occurrence of future CAD events in HD patients. The best cut-off value of AAC score is 5.5. AAC score greater than 5.5 is a reliable abdominal aortic calcification marker, and can predict future CAD in ESRD patients. Major contributive factors for higher AAC score were age, presence of diabetes, prior history of CAD, and longer dialysis vintage.
\end{abstract}

Keywords: Abdominal aortic calcification, Coronary artery disease, Hemodialysis

\section{Background}

Vascular calcification is commonly seen in chronic kidney disease (CKD) patients $[1,2]$. The prevalence of vascular calcification in end stage renal disease patients can be as high as $81 \%$ in a cross-sectional study [3]. The Kidney Disease Improving Global Outcome (KDIGO) guideline has

\footnotetext{
* Correspondence: ma273737@gmail.com

${ }^{2}$ College of Medicine, China Medical University, Taichung, Taiwan

${ }^{3}$ Division of Nephrology, China Medical University Hospital, Taichung 40447 , Taiwan

Full list of author information is available at the end of the article
}

recommended routine lateral plain radiograph in CKD stage 3-5D patients since 2009 [4]. A plain lateral lumbar graphic film can provide possible information about CKD-MBD (Mineral Bone Disease) status, vascular calcification, and cardiovascular risk for patients. Abdominal aortic calcification had been used as an indicator of vascular calcification of hemodialysis patients in previous studies [5]. Presence of abdominal aortic calcification (AAC) was associated with higher cardiovascular mortality and can be a novel marker for atherosclerosis risk in hemodialysis patients $[5,6]$. However, using severity of

(c) The Author(s). 2018 Open Access This article is distributed under the terms of the Creative Commons Attribution 4.0 International License (http://creativecommons.org/licenses/by/4.0/), which permits unrestricted use, distribution, and 
AAC to predict coronary artery disease (CAD) in chronic HD patients has not yet been investigated. The severity of AAC can be measured by a semi-quantitative method or AAC score as proposed by Kauppila LI et al. in 1977 [7]. We conducted a 5-year prospective cohort study in chronic HD patients to analyze the relationship between AAC score and future CAD events.

\section{Methods}

End-Stage Renal Disease (ESRD) patients on chronic hemodialysis (dialysis vintage longer than 3 months) in China Medicine University Hospital were included in this prospective cohort study. We recruited hemodialysis patients on maintenance hemodialysis from January 2013 to April 2018. Patients' baseline abdominal aortic calcification scores were measured by lateral lumbar $\mathrm{x}$-ray in the day of recruitment. Two physicians blind to patients' clinical information performed the AAC score calculation via a 24-point scoring system developed by Kauppila LI et al. [7]. Calcification scores of the anterior and posterior wall of abdominal aorta over 1st lumbar spine to 4th lumbar spine (L1 to L4) were recorded. Calcification score of each section ranges from 0 to 3 . Score 0 represents without any calcification; score 1 represents calcification length less than $1 / 3$ of vertebra; score 2 represents the calcification length spanned from $1 / 3$ to $2 / 3$ of vertebra; score 3 represents calcification length greater than $2 / 3$ of vertebra. AAC score is the sum of calcification score from L1 to L4 with a maximum of 24 . AAC score 0 represents no abdominal aortic calcification in lateral lumbar $\mathrm{x}$-ray and AAC score 24 represents a most severe degree of abdominal aortic calcification in lateral lumbar $\mathrm{x}$-ray.

All patients underwent hemodialysis treatment in a 3.5-4 $\mathrm{h}$ session bi-weekly or thrice-weekly, using high-flux artificial kidneys with low molecular weight heparin as anticoagulant. The quality of water for hemodialysis was monitored regularly following the standards of Association for the Advancement of Medical Instrument (AAMI) guidelines for dialysis water. Patients' clinical laboratory data, including serum albumin, creatinine, uric acid, total cholesterol, triglyceride, fasting blood sugar, calcium, phosphate, sodium, potassium, alanine aminotransferase (ALT), alkaline phosphatase (ALKP), white cell count, hemoglobin, intact parathyroid hormone (iPTH), ferritin, body mass index (BMI), and $\mathrm{spKt} / \mathrm{V}$ were obtained at recruitment day. Dialysis adequacy, spKt/V, was measured by the second-generation single-pool Daugirdas formula [8]. Diabetes mellitus (DM) was defined as hypoglycemic agents using or a fasting blood sugar level of $126 \mathrm{mg} / \mathrm{dl}$ or more [9]. Hypertension was defined as antihypertensive agents use, systolic blood pressure greater than $140 \mathrm{mmHg}$, or diastolic blood pressure greater than $90 \mathrm{mmHg}$ [10].
CAD was defined by the presence of angina, electrocardiographic changes, and elevation of cardiac enzymes [11]. Coronary angiography was performed for all the CAD patients. Follow up time defined as from patient recruitment to $\mathrm{CAD}$ occurrence or patient mortality or the ending of the study follow up set at April 2018. The study was approved by the China Medical University \& Hospital Research Ethics Committee, Taiwan (Reference number: CMUH-104-REC1-110). Blood sampling and lumbar spine $\mathrm{x}$-ray from all study subjects was performed after obtaining informed consent.

\section{Statistical analysis}

Continuous data passing normality test were reported as mean \pm standard deviation, continuous data failed to pass normality test were reported as median with interquartile range. Parametric variables were analyzed by Student's $t$ test, and non-parametric variables were analyzed by Kolmogorov-Smirnov test. Chi-square test was applied for categorical variables. A $p$-value $<0.05$ was considered statistically significant. The association between AAC score and factors related to CAD were analyzed using univariate Cox regression model. Associated confounders with a $p<0.05$ were further analyzed by multivariable Cox regression. ROC (receiver operative curve) curve analysis found the best cutoff value of AAC for CAD prediction. CAD-free survival rate in groups with high or low AAC score were plotted into Kaplan-Meier survival curves. Factors associated with higher AAC score group and non-traditional vascular calcification markers (serum calcium, phosphate, iPTH, clearance of dialysis) were analyzed by multivariate linear regression model. All analyses were performed using SPSS for windows version 18 (IBM Corporation, Chicago, IL, USA).

\section{Results}

We recruited 303 ESRD patients on chronic HD for this study. The demographic data and baseline biochemistries are shown in Table 1 . The median age of these patients was $63(56-71)$ years old, and 51.5\% $(n=156)$ among them were females. The proportion of patients with diabetes was $47 \%(n=142)$, with hypertension was $81.5 \%(n=247)$, and with prior history of coronary artery disease was $27 \%(n=$ $82)$. The medium value of HD vintage was 95 (65-146) months and the median follow-up duration was 68.5 (39.7$68.5)$ months. The medium value of AAC score in all these patients was $6.0(2.0-12.0)$. Acute CAD events occurred in $37.6 \%(n=114)$ of the patients during follow-up period. All cause-mortality rate was $22.1 \%(n=67)$ while $42 \%(9.2 \%(n$ $=28)$ ) of death were cardiovascular-related mortality (CAD, sudden cardiac arrest and peripheral arterial occlusive disease with infection). 
Table 1 Demographic parameters of hemodialysis patients without and with occurrence of CAD event during follow-up period

\begin{tabular}{|c|c|c|c|}
\hline & $\begin{array}{l}\text { Without CAD } \\
n=189\end{array}$ & $\begin{array}{l}\text { With CAD } \\
n=114\end{array}$ & $p$ \\
\hline Age(years old) & $62.1(54.1-71.0)$ & $64.0(59.0-71.0)$ & 0.114 \\
\hline Male (n, \%) & $83(44 \%)$ & $64(56 \%)$ & 0.039 \\
\hline $\mathrm{DM}(\mathrm{n}, \%)$ & 73 (39\%) & 69 (61\%) & $<0.001$ \\
\hline HTN (n, \%) & $152(80 \%)$ & 95 (83\%) & 0.527 \\
\hline CAD history (n, \%) & $23(12 \%)$ & $59(52 \%)$ & $<0.001$ \\
\hline Vintage (months) & $95.0(64.0-147.0)$ & $95.0(65.8-141.8)$ & 0.853 \\
\hline $\mathrm{BMI}\left(\mathrm{kg} / \mathrm{m}^{2}\right)$ & $22.1(19.9-24.1)$ & $23.5(21.4-25.4)$ & 0.001 \\
\hline Hemogloblin (gm/dl) & $10.9(10.1-11.5)$ & $10.7(10.1-11.5)$ & 0.770 \\
\hline White blood cell $\left(10^{3} / \mathrm{uL}\right)$ & $6.3(4.7-7.9)$ & $6.5(5.7-7.8)$ & 0.053 \\
\hline Albumin (gm/dl) & $4.1(3.9-4.3)$ & $4.1(3.9-4.3)$ & 0.786 \\
\hline Creatinine $(\mathrm{mg} / \mathrm{dl})$ & $10.6(9.3-12.1)$ & $10.6(9.2-12.4)$ & 0.841 \\
\hline $\operatorname{ALT}(U / L)$ & $15(11-22)$ & $14(11-19)$ & 0.169 \\
\hline $\operatorname{ALKP}(\mathrm{U} / \mathrm{L})$ & $72(55-98)$ & $71(56-89)$ & 0.294 \\
\hline Uric acid (mg/dl) & $6.6(5.8-7.4)$ & $6.6(5.8-7.3)$ & 0.694 \\
\hline FBS (mg/dl) & $89(79-111)$ & $96(83-130)$ & 0.018 \\
\hline Cholesterol $(\mathrm{mg} / \mathrm{dl})^{\mathrm{a}}$ & $165.5 \pm 37.9$ & $152.5 \pm 35.9$ & 0.003 \\
\hline Triglyceride (mg/dl) & $106(71-161)$ & $112(84-175)$ & 0.329 \\
\hline Calcium $(\mathrm{mg} / \mathrm{dl})^{\mathrm{a}}$ & $9.47 \pm 0.84$ & $9.47 \pm 0.80$ & 0.973 \\
\hline Phosphate (mg/dl) & $5.3(4.5-6.0)$ & $5.7(4.6-6.8)$ & 0.048 \\
\hline iPTH (pg/mL) & $184(61-337)$ & $176(69-356)$ & 0.907 \\
\hline Ferritin $(\mathrm{ng} / \mathrm{mL})$ & $486(318-642)$ & $482(280-613)$ & 0.341 \\
\hline Sodium(mEq/L) & 137 (134-139) & $137(135-139)$ & 0.442 \\
\hline Potassium(mEq/L) & $5.0(4.5-5.5)$ & $5.0(4.4-5.6)$ & 0.929 \\
\hline $\mathrm{spKt} / \mathrm{N}$ & $1.39(1.24-1.52)$ & $1.27(1.14-1.44)$ & $<0.001$ \\
\hline AAC score & $5(1-9)$ & $9(3-15.25)$ & $<0.001$ \\
\hline
\end{tabular}

Abbreviations: $A A C$ score abdominal aortic calcification score, $D M$ diabetes mellitus, HTN hypertension, $C A D$ coronary artery disease, $B M I$ body mass index, $A L T$ alanine aminotransferase, ALKP alkaline phosphatase, $F B S$ fasting blood sugar, Calcium serum total calcium (corrected by albumin), iPTH intactparathyroid hormone, spKt/V: Single-pool Kt $/ \mathrm{V}$

a Parametric variables (include serum cholesterol, calcium); except this two variables, all of other continuous variables else are nonparametric

The AAC score in the group with new CAD occurrence $(9(3-15.25), \mathrm{n}=114)$ was higher than in the group without CAD occurrence (5 (1-9), $n=189)(p<$ $0.001)$. The multi-variate hazard ratio of AAC score for CAD group was $1.039(p=0.016)$ (Table 2). ROC analysis found the best AAC cutoff value for CAD prediction-an AAC score of 5.5 had a sensitivity of 0.658 and a specificity of 0.587 in the prediction of future CAD occurrence. (Figure 1) Area under curve of AAC score and CAD occurrence was $0.645(\mathrm{p}<0.001)$. Patients with AAC score above 5.5 had higher cumulative incidence of CAD than patients with AAC score below 5.5 (log-rank test, $p=0.001$ ) (Fig. 2).
Linear regression analysis was further used to identify factors significantly associated with higher AAC score. In our study group, possible cofounders for higher AAC score such as advanced age, DM, hypertension, prior history of CAD, longer dialysis vintage, high serum fasting blood sugar, triglyceride and lower serum creatinine level were analyzed. (Table 3) Other non-traditional vascular calcification contributive factors such as serum calcium, phosphate, iPTH and dialysis clearance marker $(\mathrm{spK} / \mathrm{V})$ were also considered and put into multivariate linear regression analysis. Advanced age $(p<0.001)$, presence of DM $(p=0.006)$, with prior history of CAD $(p=0.002)$ and longer dialysis vintage $(p=0.001)$ were major factors associated with higher AAC group (AAC score $>5.5$ ) (Table 4).

\section{Discussion}

The major finding of our study is that higher AAC score can predict future CAD events in chronic HD patients. After adjustment of other known confounders, we found that the hazard ratios of AAC for CAD was 1.039 in multivariate Cox-regression model, $p=0.016$. One point of AAC score increase was associated with $4 \%$ increase in the risk of future CAD events. The CAD-free survival rate was lower in high $\mathrm{AAC}$ score group (AAC score $>$ 5.5) than in low AAC score group (AAC score $<5.5$ ) with statistic significance $(p=0.001)$. We demonstrated that AAC score, independently of other contributive factors (prior history of CAD and higher BMI value), successfully predicted future CAD events in HD patients.

The most important contributive factors for future CAD occurrence in our study were prior history of CAD and BMI. In CKD population, patients with preexisting cardiovascular disease had been reported to be associated with an increased risk for recurrent cardiovascular outcome [12]. In our finding, patients with higher BMI were also associated with future CAD events. The majority (88\%) of our study cases' BMI ranged from normal to overweight by the BMI criteria for Asian populations [13]. The BMI distribution of our study subjects was as follows: 70\% of patients' BMI 18.5-25 (normal); 18\% BMI 25-30 (overweight); 9\% BMI $<18.5$ (underweight); $3 \%$ BMI > 30 (obesity). Higher BMI had been reported to be associated with inflammation in HD patients [14], and was compatible with our finding that higher BMI, with a more severe inflammatory status, may increase the incidence of future CAD events.

In our cohort study, traditional cardiovascular risk factors, such as diabetes, baseline fasting blood sugar, serum phosphate level, did not influence the future coronary artery disease. Although the characteristics of these traditional parameters significantly increased the risk of CAD in univariate Cox regression model (Table 2, Model 1, crude hazard ratio), they did not statistically 
Table 2 Hazard ratios of different variable on occurrence of CAD

\begin{tabular}{|c|c|c|c|c|}
\hline \multirow[b]{2}{*}{ Variable } & \multicolumn{2}{|l|}{ Model 1} & \multicolumn{2}{|l|}{ Model 2} \\
\hline & $\mathrm{HR}(95 \% \mathrm{Cl})$ & $p$ & $\mathrm{HR}(95 \% \mathrm{Cl})$ & $p$ \\
\hline AAC (per 1 score increase) & $1.071(1.043-1.099)$ & $<0.001$ & $1.039(1.007-1.071)$ & 0.016 \\
\hline CAD history (Ref: no) & $5.314(3.659-7.718)$ & $<0.001$ & $3.816(2.531-5.752)$ & $<0.001$ \\
\hline Age (per 1 year old increase) & $1.016(1.000-1.032)$ & 0.045 & $1.013(0.994-1.032)$ & 0.185 \\
\hline Gender (Ref: female) & $1.510(1.043-2.186)$ & 0.029 & $1.162(0.766-1.763)$ & 0.481 \\
\hline DM (Ref: no) & $2.089(1.434-3.042)$ & $<0.001$ & $1.359(0.878-2.102)$ & 0.169 \\
\hline HTN (Ref: no) & $1.156(0.706-1.892)$ & 0.564 & $0.921(0.550-1.543)$ & 0.754 \\
\hline Vintage (per 1 month increase) & $1.000(0.997-1.003)$ & 0.985 & $1.001(0.998-1.005)$ & 0.415 \\
\hline BMI (per 1 kg/m² increase) & $1.071(1.020-1.124)$ & 0.006 & $1.077(1.015-1.142)$ & 0.013 \\
\hline FBS (per 1 mg/dl increase) & $1.003(1.001-1.006)$ & 0.020 & $1.000(0.996-1.003)$ & 0.913 \\
\hline Cholesterol (per 1 mg/dl increase) & $0.992(0.987-0.997)$ & 0.002 & $0.996(0.990-1.001)$ & 0.088 \\
\hline Phosphate (per 1 mg/dl increase) & $1.148(1.012-1.303)$ & 0.032 & $1.090(0.947-1.254)$ & 0.231 \\
\hline spKt/N (per 1 unit increase) & $0.244(0.108-0.552)$ & 0.001 & $0.502(0.186-1.349)$ & 0.172 \\
\hline
\end{tabular}

Model 1: crude hazard ratio; Model 2: adjusted for all variables

Abbreviations: $A A C$ score abdominal aortic calcification score, DM diabetes mellitus, HTN hypertension, CAD coronary artery disease, BMI body mass index, FBS fasting blood sugar, spKt/N Single-pool Kt/V

influence the risk of future cardiovascular disease after adjustment of all known confounders (Table 2, Model 2, adjusted hazard ratio). AAC score, however, significantly increased the multivariate hazard ratios in Cox-regression analysis.

In univariate model, hypocholesterolemia increased the risk for future CAD events, we though the major reason is related to the uremic inflammation status.

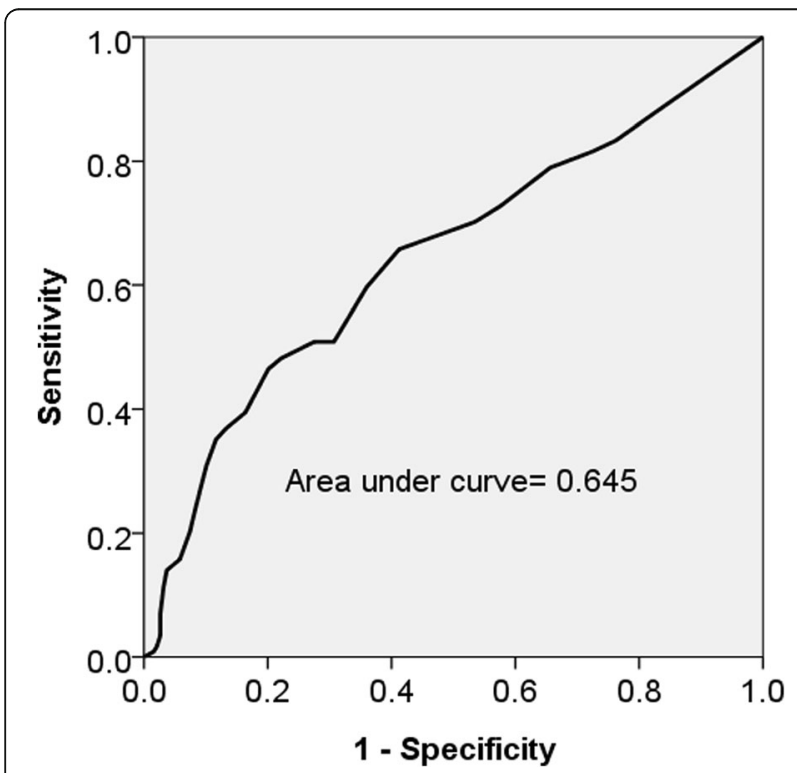

Fig. 1 Receiver operating charactiristic (ROC) analysis of abdominal aortic calcification (AAC) score and the risk of future coronary artery disease (CAD). ROC study showed an area under curve of 0.645 $(p<0.001)$. An AAC score grear than 5.5 was associated with future CAD occurence with a sensitivity of 0.658 and a specificity of 0.587
Reverse epidemiology of cardiovascular events in maintenance HD patients had been reported [15]. In ESRD patients, hypocholesteremia reflected higher inflammation and likelihood of malnutrition inflammation. These patients tended to have higher CAD risk because of uremic inflammation. However, serum cholesterol appeared to not influence CAD prediction in our multivariate Cox regression analysis.

Recently, we have shown that a positive association between AAC score and new CAD event in ESRD patients on peritoneal dialysis [16]. In prior study, we found AAC score greater than 5.5 predicted future CAD events

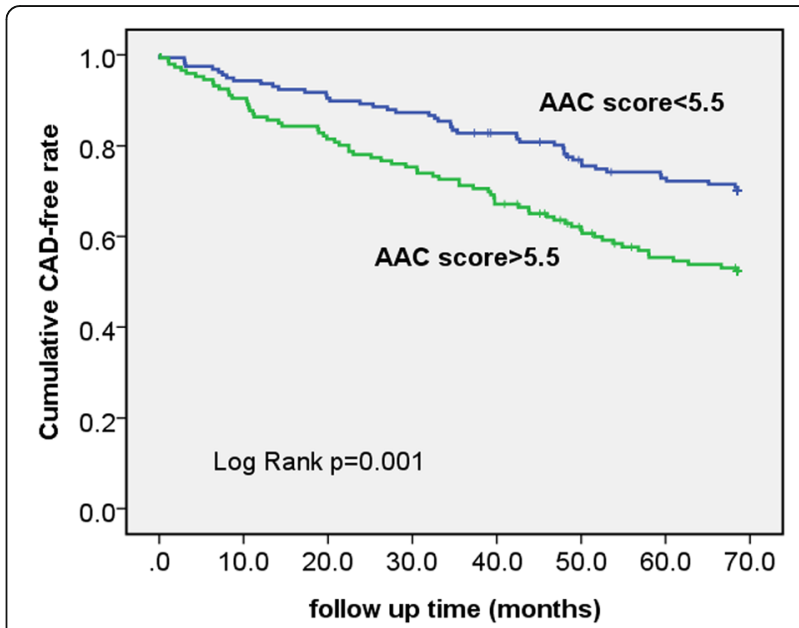

Fig. 2 CAD-free survival of patients with AAC score below and above 5.5. Kaplan-Meier study showed hemodialysis dialysis ptients with AAC score lower than 5.5 had a higher cumulative CAD-free survival than that of patients with AAC score higher than 5.5 $(p=0.001$, log-rank test $)$ 
Table 3 Demographic parameters of hemodialysis patients with AAC score below and above 5.5

\begin{tabular}{|c|c|c|c|}
\hline \multirow[t]{2}{*}{ Group } & \multirow{2}{*}{$\begin{array}{l}\mathrm{AAC}<5.5 \\
n=157\end{array}$} & \multicolumn{2}{|l|}{$\mathrm{AAC}>5.5$} \\
\hline & & $n=146$ & $p$ \\
\hline Age(years old) & $61.0(53.0-68.0)$ & $65.0(60.0-73.3)$ & $<0.001$ \\
\hline Male (n, \%) & $81(52 \%)$ & $66(45 \%)$ & 0.266 \\
\hline $\mathrm{DM}(\mathrm{n}, \%)$ & $57(36 \%)$ & $85(58 \%)$ & $<0.001$ \\
\hline HTN (n, \%) & $127(81 \%)$ & $120(82 \%)$ & 0.771 \\
\hline CAD history (n, \%) & $26(17 \%)$ & $56(38 \%)$ & $<0.001$ \\
\hline Vintage (months) & $88.0(62.5-145.0)$ & $102.5(75.8-148.0)$ & 0.029 \\
\hline $\mathrm{BMI}\left(\mathrm{kg} / \mathrm{m}^{2}\right)$ & $22.4(20.3-24.5)$ & $22.8(20.7-24.6)$ & 0.965 \\
\hline Hemogloblin (gm/dl) & $10.8(10.1-11.4)$ & $10.9(9.9-11.6)$ & 0.915 \\
\hline White blood cell $\left(10^{3} / \mathrm{uL}\right)$ & $6.3(4.9-7.8)$ & $6.7(5.5-8.0)$ & 0.177 \\
\hline Albumin $(\mathrm{gm} / \mathrm{dl})$ & $4.1(3.9-4.3)$ & $4.1(3.9-4.3)$ & 0.755 \\
\hline Creatinine $(\mathrm{mg} / \mathrm{dl})$ & $11.0(9.8-12.6)$ & $10.2(9.1-11.6)$ & 0.002 \\
\hline $\operatorname{ALT}(U / L)$ & $15(11.5-21.5)$ & $14(11-20)$ & 0.521 \\
\hline $\operatorname{ALKP}(\mathrm{U} / \mathrm{L})$ & $71(51-93)$ & $73(58-92)$ & 0.349 \\
\hline Uric acid (mg/dl) & $6.6(5.9-7.4)$ & $6.6(5.8-7.3)$ & 0.679 \\
\hline $\mathrm{FBS}(\mathrm{mg} / \mathrm{dl})$ & $90(78-109)$ & $93(82-125)$ & 0.029 \\
\hline Cholesterol $(\mathrm{mg} / \mathrm{dl})^{\mathrm{a}}$ & $162 \pm 35$ & $159 \pm 40$ & 0.482 \\
\hline Triglyceride (mg/dl) & $103(63-154)$ & $112(83-174)$ & 0.028 \\
\hline Calcium $(\mathrm{mg} / \mathrm{dll})^{\mathrm{a}}$ & $9.46 \pm 0.86$ & $9.48 \pm 0.79$ & 0.810 \\
\hline Phosphate (mg/dl) & $5.4(4.5-6.2)$ & $5.5(4.6-6.5)$ & 0.320 \\
\hline iPTH (pg/mL) & $184(60-328)$ & $177(68-362)$ & 0.609 \\
\hline Ferritin (ng/mL) & $478(271-631)$ & $496(356-645)$ & 0.346 \\
\hline Sodium(mEq/L) & 137 (135-139) & $137(134-138)$ & 0.404 \\
\hline Potassium(mEq/L) & $4.9(4.5-5.5)$ & $5.0(4.5-5.6)$ & 0.964 \\
\hline spKt/N & $1.34(1.19-1.47)$ & $1.35(1.20-1.50)$ & 0.557 \\
\hline
\end{tabular}

Abbreviations: $A A C$ score abdominal aortic calcification score, $D M$ diabetes mellitus, HTN hypertension, CAD coronary artery disease, BMI body mass index, $A L T$ alanine aminotransferase, $A L K P$ alkaline phosphatase, $F B S$ fasting blood sugar, Calcium serum total calcium (corrected by albumin), iPTH intactparathyroid hormone, spKt/ $/$ Single-pool Kt $/ V$

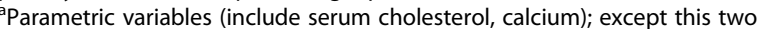
variables, all of other continuous variables else are nonparametric

( $p=0.003, \log$-rank test in Kaplan Meier study). In this study, AAC score greater than 5.5 can also predict CAD in hemodialysis patients. Thus, we believe that the best cut-off value of AAC score is 5.5 to predict CAD in ESRD patients. In the previous study on peritoneal patients, the risk factors of higher AAC score were age, duration of dialysis, presence of diabetes, and history of cardiovascular disease [3, 17]. Our current study on hemodialysis patients, compatible with the results on peritoneal dialysis patients [16], also showed the above mentioned factors were associated with high AAC score.

Dyslipidemia with production of oxidatively modified LDL (or oxidized LDL, oxLDL) is the main hypothesis of CAD in general population. Macrophage uptakes oxLDL and triggers immune reaction. This inflammatory process leads to endothelial dysfunction, atherosclerosis, and
Table 4 Related confounders of higher AAC score group (AAC score $>5.5)$ in multivariate linear regression

\begin{tabular}{lll}
\hline & \multicolumn{2}{l}{ Higher AAC score group } \\
\cline { 2 - 3 } & Beta & $p$ value \\
\hline Age(per 1 year old increase) & 0.238 & $<\mathbf{0 . 0 0 1}$ \\
DM (Ref: no) & 0.179 & $\mathbf{0 . 0 0 6}$ \\
HTN (Ref: no) & 0.002 & 0.975 \\
CAD history (Ref: no) & 0.177 & $\mathbf{0 . 0 0 2}$ \\
Vintage (per 1 month increase) & 0.189 & $\mathbf{0 . 0 0 1}$ \\
BMI (per 1 kg/m² increase) & -0.048 & 0.440 \\
Creatinine(per 1 mg/dl increase) & -0.014 & 0.832 \\
Fasting blood sugar (per 1 mg/dl increase) & 0.009 & 0.885 \\
Triglyceride(per 1 mg/dl increase) & -0.004 & 0.950 \\
iPTH (per 1 pg/mL increase) & 0.035 & 0.580 \\
Calcium (per 1 mg/dl increase) & 0.001 & 0.988 \\
Phosphate (per 1 mg/dl increase) & 0.084 & 0.170 \\
spKt $N$ (per 1 unit increase) & -0.005 & 0.941 \\
\hline
\end{tabular}

Abbreviations: $A A C$ score abdominal aortic calcification score, $D M$ diabetes mellitus, HTN hypertension, CAD Coronary artery disease, IPTH intactparathyroid hormone, spKt/V Single-pool Kt/V

clinical cardiovascular disease [18]. Therefore, oxidative stress with endothelial dysfunction has been known to be the major pathogenic factors associated with $\operatorname{CAD}[19,20]$. CAD is highly prevalent in ESRD patients and results in high mortality and poor long term survival [21]. CKD per se had long been proven to be associated with oxidative stress and endothelial dysfunction [22, 23]. The markedly increased oxidation and impaired endothelial function can also be seen in ESRD patients [24]. Treatment of dyslipidemia in hemodialysis patients, however, did not decrease the CAD incidence in these patient group (4D, AURORA, SHARP study) [25-27]. Factors other than dyslipidemia may be the $\mathrm{CAD}$ maker in hemodialysis patients.

Vascular calcification is also a manifestation of atherosclerosis and a cardiovascular risk factor in chronic kidney disease and uremia patients $[28,29]$. The mechanism for atherosclerosis is quite different in CKD population. Mechanism of osteogenic transdifferentiation of vascular smooth muscle reported in CKD [30] contributed to medial layer vascular calcification [31]. As abdominal aortic calcification can be an indicator of vascular calcification, our results may implicate AAC as a marker of $\mathrm{CAD}$ in hemodialysis patients. By measuring the abdominal aortic calcification, we can sooner identify the higher risk CAD patients in patients on maintenance hemodialysis and may further prevent occurrence in these patients.

\section{Limitations}

There are still some limitations in our study. First, this is a prospective observation cohort study in one single 
center. Second, we had a low prevalence of calcimimetic agent use $(<5 \%)$, an important issue in patients' outcome with secondary hyperparathyroidism and mineral bone disease on maintenance hemodialysis. We cannot further analyze the effect on vascular calcification.

\section{Conclusions}

AAC score can predict occurrence of new CAD events in chronic hemodialysis patients. The best cut-off value of AAC score is 5.5. AAC score greater than 5.5 is a reliable abdominal aortic calcification marker, and can predict future CAD in ESRD patients. In hemodialysis patients, major contributive factors for higher AAC score are advanced age, presence of diabetes, with prior history of CAD and longer dialysis vintage.

\begin{abstract}
Abbreviations
4D study: Die Deutsche Diabetes Dialyse Studie; AAC: Abdominal aortic calcification; ALKP: Alkaine phosphatase; ALT: Alanine aminotransferase: AURORA study: A Study to Evaluate the Use of Rosuvastatin in Subjects on Regular Hemodialysis: An Assessment of Survival and Cardiovascular Events; BMI: Body mass index; CAD: Coronary artery disease; CKD: Chronic kidney disease; CKD-MBD: Chronic kidney disease-mineral bone disease; DM: Dabetes mellitus; ESRD: End-Stage Renal Disease; FBS: Fasting blood sugar; HD: Hemodialysis; HTN: Hypertension; iPTH: Intact parathyroid hormone; KDIGO: The Kidney Disease Improving Global Outcome; LDL: Lowdensity lipoprotein; ROC: Receiver operation curve; SHARP study: Study of Heart and Renal Protection; spKt/N: Single-pool Kt/N
\end{abstract}

\section{Acknowledgements}

Wei-Ting Wang and Chieh-Ning Hsi are medical students of School of Medicine, China Medical University, Taiwan.

\section{Funding}

The study was sponsored by China Medical University Hospital, Taiwan (DMR-106-027) and Ministry of Science and Technology, Taiwan (Funding Number: 107-2813-C-039-295-B). The funding bodies approved the design of study and data acquisition method, but did not involve in data analysis, and manuscript writing.

\section{Availability of data and materials}

The datasets used and/or analyzed during the current study are available from the corresponding author upon request.

\section{Authors' contributions}

HCC: study design, data acquisition, analysis, study design, and manuscript writing; WTW: data acquisition, data analysis, and manuscript writing; $\mathrm{CNH}$ : data acquisition, data analysis, and manuscript writing; CYC: study design, data analysis and data interpretation; HJL: study design, data acquisition, and data interpretation; CCH: data acquisition, study concept and, study design; CTC: study design, study concept, data analysis, data interpretation, and manuscript writing. All authors read and gave approval to the manuscript to be published.

\section{Ethics approval and consent to participate}

All participants in this study provided informed consent. The study was approved by the China Medical University \& Hospital Research Ethics Committee (Reference number: CMUH-104-REC1-110). The patient recruitment followed the institutional review board (IRB) guidelines and all patients signed a written inform consent.

\section{Competing interests}

The authors declare that there is no competing interest in the study.

\section{Publisher's Note}

Springer Nature remains neutral with regard to jurisdictional claims in published maps and institutional affiliations.

\section{Author details}

${ }^{1}$ Division of Nephrology, Asia University Hospital, Taichung, Taiwan. ${ }^{2}$ College of Medicine, China Medical University, Taichung, Taiwan. ${ }^{3}$ Division of Nephrology, China Medical University Hospital, Taichung 40447, Taiwan.

Received: 23 August 2018 Accepted: 26 October 2018

Published online: 08 November 2018

\section{References}

1. Goodman WG, London G, Amann K, Block GA, Giachelli C, Hruska KA, Ketteler M, Levin A, Massy Z, McCarron DA, et al. Vascular calcification in chronic kidney disease. Am J Kidney Dis. 2004;43(3):572-9.

2. Peeters MJ, van den Brand JA, van Zuilen AD, Koster $Y$, Bots ML, Vervloet MG, Blankestijn PJ, Wetzels JF, Group MS. Abdominal aortic calcification in patients with CKD. J Nephrol. 2017;30(1):109-18.

3. Honkanen E, Kauppila L, Wikstrom B, Rensma PL, Krzesinski JM, Aasarod K, Verbeke F, Jensen PB, Mattelaer P, Volck B, et al. Abdominal aortic calcification in dialysis patients: results of the CORD study. Nephrol Dial Transplant. 2008;23(12):4009-15.

4. Kidney Disease: Improving Global Outcomes (KDIGO) CKD-MBD Work Group. Chapter 3.1: Diagnosis of CKD-MBD: bichemical abnormalities. Kidney Int. 2009;76113:S22-49.

5. Pencak P, Czerwienska B, Ficek R, Wyskida K, Kujawa-Szewieczek A, Olszanecka-Glinianowicz M, Wiecek A, Chudek J. Calcification of coronary arteries and abdominal aorta in relation to traditional and novel risk factors of atherosclerosis in hemodialysis patients. BMC Nephrol. 2013;14:10.

6. Okuno S, Ishimura E, Kitatani K, Fujino Y, Kohno K, Maeno Y, Maekawa K, Yamakawa T, Imanishi $Y$, Inaba $M$, et al. Presence of abdominal aortic calcification is significantly associated with all-cause and cardiovascular mortality in maintenance hemodialysis patients. Am J Kidney Dis. 2007;49(3): $417-25$

7. Kauppila LI, Polak JF, Cupples LA, Hannan MT, Kiel DP, Wilson PW. New indices to classify location, severity and progression of calcific lesions in the abdominal aorta: a 25-year follow-up study. Atherosclerosis. 1997;132(2): 245-50.

8. Daugirdas JT. Second generation logarithmic estimates of single-pool variable volume Kt/N: an analysis of error. J Am Soc Nephrol. 1993;4(5): 1205-13.

9. Gottlieb DJ, Punjabi NM, Newman AB, Resnick HE, Redline S, Baldwin CM, Nieto FJ. Association of sleep time with diabetes mellitus and impaired glucose tolerance. Arch Intern Med. 2005;165(8):863-7.

10. Lavie $\mathrm{P}$, Herer $\mathrm{P}$, Hoffstein V. Obstructive sleep apnoea syndrome as a risk factor for hypertension: population study. BMJ. 2000;320(7233):479-82.

11. Chang CP, Li TC, Hang LW, Liang SJ, Lin JJ, Chou CY, Tsai JJ, Ko PY, Chang $C T$. The relationships of sleep apnea, hypertension, and resistant hypertension on chronic kidney disease. Medicine (Baltimore). 2016;95(23): e3859.

12. Weiner DE, Tighiouart H, Stark PC, Amin MG, MacLeod B, Griffith JL, Salem DN, Levey AS, Sarnak MJ. Kidney disease as a risk factor for recurrent cardiovascular disease and mortality. Am J Kidney Dis. 2004:44(2):198-206.

13. Cole TJ, Bellizzi MC, Flegal KM, Dietz WH. Establishing a standard definition for child overweight and obesity worldwide: international survey. BMJ. 2000; 320(7244):1240-3

14. Kahraman S, Yilmaz R, Akinci D, Arici M, Altun B, Erdem Y, Yasavul U, Turgan C. U-shaped association of body mass index with inflammation and atherosclerosis in hemodialysis patients. J Ren Nutr. 2005;15(4):377-86.

15. Kalantar-Zadeh K, Block G, Humphreys MH, Kopple JD. Reverse epidemiology of cardiovascular risk factors in maintenance dialysis patients. Kidney Int. 2003;63(3):793-808

16. Chen HC, Chou CY, Lin HJ, Huang CC, Chang CT. Abdominal aortic calcification score predicts the occurrence of coronary artery disease in middle-aged peritoneal dialysis patients. Nephrology (Carlton). 2018.

17. Chen HC, Chou CY, Jheng JS, Chen IR, Liang CC, Wang SM, Liu JH, Lin SY, Kuo $\mathrm{HL}$, Wang IK, et al. Loss of residual renal function is associated with vascular calcification in hemodialysis patients. Ther Apher Dial. 2016;20(1): 27-30. 
18. Witztum JL. The oxidation hypothesis of atherosclerosis. Lancet. 1994; 344(8925):793-5.

19. Cai H, Harrison DG. Endothelial dysfunction in cardiovascular diseases: the role of oxidant stress. Circ Res. 2000;87(10):840-4.

20. Heitzer T, Schlinzig T, Krohn K, Meinertz T, Munzel T. Endothelial dysfunction, oxidative stress, and risk of cardiovascular events in patients with coronary artery disease. Circulation. 2001;104(22):2673-8.

21. Herzog CA, Ma JZ, Collins AJ. Poor long-term survival after acute myocardial infarction among patients on long-term dialysis. N Engl J Med. 1998;339(12): 799-805.

22. Yilmaz MI, Saglam M, Caglar K, Cakir E, Sonmez A, Ozgurtas T, Aydin A Eyileten T, Ozcan O, Acikel C, et al. The determinants of endothelial dysfunction in CKD: oxidative stress and asymmetric dimethylarginine. Am J Kidney Dis. 2006;47(1):42-50.

23. Dounousi E, Papavasiliou E, Makedou A, loannou K, Katopodis KP, Tselepis A, Siamopoulos KC, Tsakiris D. Oxidative stress is progressively enhanced with advancing stages of CKD. Am J Kidney Dis. 2006;48(5):752-60.

24. Himmelfarb J, Stenvinkel P, Ikizler TA, Hakim RM. The elephant in uremia: oxidant stress as a unifying concept of cardiovascular disease in uremia. Kidney Int. 2002;62(5):1524-38.

25. Langer A. Atorvastatin in patients with type 2 diabetes mellitus undergoing dialysis. N Engl J Med. 2005;353(17):1858-60 author reply 1858-1860.

26. Fellstrom BC, Jardine AG, Schmieder RE, Holdaas H, Bannister K, Beutler J, Chae DW, Chevaile A, Cobbe SM, Gronhagen-Riska C, et al. Rosuvastatin and cardiovascular events in patients undergoing hemodialysis. N Engl J Med. 2009:360(14):1395-407.

27. Sharp Collaborative G. Study of heart and renal protection (SHARP): randomized trial to assess the effects of lowering low-density lipoprotein cholesterol among 9,438 patients with chronic kidney disease. Am Heart J. 2010;160(5):785-94 e710.

28. Mizobuchi M, Towler D, Slatopolsky E. Vascular calcification: the killer of patients with chronic kidney disease. J Am Soc Nephrol. 2009;20(7):1453-64

29. Jablonski KL, Chonchol M. Vascular calcification in end-stage renal disease. Hemodial Int. 2013;17(Suppl 1):S17-21.

30. Ketteler M, Rothe H, Kruger T, Biggar PH, Schlieper G. Mechanisms and treatment of extraosseous calcification in chronic kidney disease. Nat Rev Nephrol. 2011;7(9):509-16.

31. Shroff RC, McNair R, Figg N, Skepper JN, Schurgers L, Gupta A, Hiorns M, Donald AE, Deanfield J, Rees $L$, et al. Dialysis accelerates medial vascular calcification in part by triggering smooth muscle cell apoptosis. Circulation. 2008;118(17):1748-57.

Ready to submit your research? Choose BMC and benefit from:

- fast, convenient online submission

- thorough peer review by experienced researchers in your field

- rapid publication on acceptance

- support for research data, including large and complex data types

- gold Open Access which fosters wider collaboration and increased citations

- maximum visibility for your research: over $100 \mathrm{M}$ website views per year

At $\mathrm{BMC}$, research is always in progress.

Learn more biomedcentral.com/submissions 